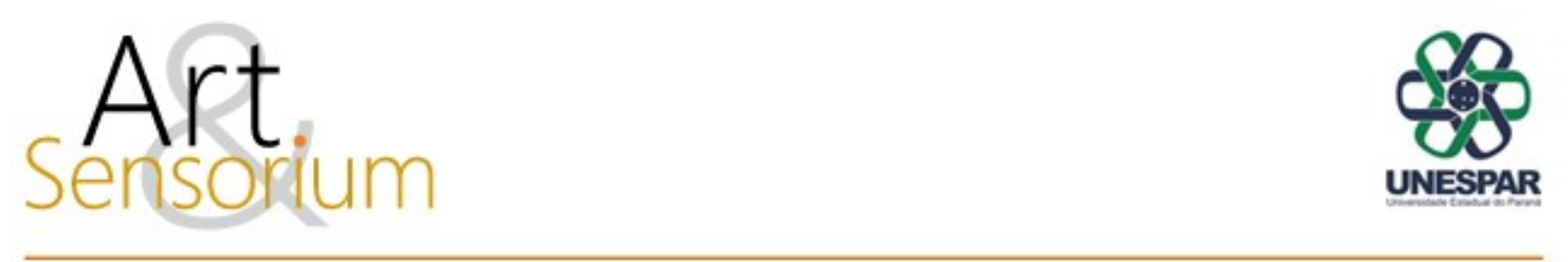

\title{
NINFAS E MONSTROS: \\ O PÓS-VIDA DE CRIATURAS FANTÁSTICAS NA IMAGINAÇÃO HUMANA
}

DOI: https://doi.org/10.33871/23580437.2021.8.2.271-284

\author{
Felipe Lima Rodrigues ${ }^{1}$ \\ Gabriela Frota Reinaldo ${ }^{2}$
}

\begin{abstract}
Resumo: Este ensaio busca vasculhar as trevas pelas quais os monstros transitam a fim de compreender como esses seres se relacionam com as ninfas discutidas pelo historiador da arte e estudioso das imagens Aby Warburg. Ninfas e monstros compartilham características como a eterealidade de seus corpos, o estranhamento causado por suas figuras e o deslocamento temporal de suas presenças. Para Warburg, as imagens das ninfas na arte renascentistas são manifestações de pathosformeln antigas, heranças do passado, engramas no sistema nervoso dos indivíduos. Os monstros, por sua vez, trazem inscritos em seus corpos advertências ancestrais (Cohen, 2000). Mais que isso, vampiros, medusas e demônios persistem na cultura, em processo de nachleben - termo caro a Aby Warburg - um processo transmissão, recepção e polarização. Assim, embora simbolicamente se situem em polos distintos, ninfas e monstros se encontram na dimensão do inesperado, do imprevisto, do acidental: enquanto as ninfas de Warburg pairam misteriosamente, flutuando imprudentemente nas obras do Quattrocento italiano como persistência do paganismo no cenário cristão, as bestas deformadas da imaginação humana espreitam nas sombras prontas para saltar sobre os que cruzam os seus caminhos. O encontro com ninfas ou monstros é irreparável dele, não saímos ilesos/as.
\end{abstract}

Palavras-Chave: Monstro; Nachleben; Pathosformeln.

\section{NYMPHS AND MONSTERS: THE AFTER LIFE OF FANTASTIC CREATURES IN HUMAN IMAGINATION}

\begin{abstract}
This essay aims to search the darkness in which monsters wander to understand how these beings relate to the nymphs described by the art historian and image scholar Aby Warburg in his works. Nymphs and monstes share features, such as their bodies ethereality, the strangeness

\footnotetext{
${ }^{1}$ Felipe Lima Rodrigues é doutorando pelo Programa de Pós-Graduação em Comunicação da Universidade Federal do Ceará, o PPGCom-UFC. O ensaio aqui apresentado é um fragmento de uma pesquisa de maior fôlego que tem sido desenvolvida ao longo do mestrado e doutorado, que examina o tema da monstruosidade na cultura (especialmente em representações como literatura, quadrinhos, no pop e no cinema). Fortaleza, Ceará, Brasil. Lattes: http://lattes.cnpq.br/1870338414302204. Orcid: https:/orcid.org/0000-0001-8583-989X . E-mail: felipelima2005@gmail.com.

2 Professora orientadora. Doutora em Comunicação e Semiótica pela PUC/SP, Gabriela Reinaldo é professora permanente no Programa de Programa de Pós-Graduação em Comunicação da Universidade Federal do Ceará e professora do Programa de Pós-Graduação em Comunicação (PPGCOM) e do Instituto de Cultura e Arte (ICA) da UFC. Coordena juntamente com o professor Osmar Gonçalves (UFC) o IMAGO Laboratório de Estudos de Estética e Imagem. Currículo Lattes: http://lattes.cnpq.br/3885064446506872. Orcid: https://orcid.org/0000-0003-3663-0314. Email: gabriela.reinaldo@gmail.com.
} 
caused by their figures, de temporal shift of their presence. For Warburg, the nymphs' images in renaissance art are manifestation of ancient pathosformeln, heritage of the past, engrams on the nervous system of individuals. The monsters, in its turn, bring old warnings inscribed in their bodies (Cohen, 2000). More than that, vampires, medusas and demons persist in culture, in nachleben - a word cherished to Warburg - a process of transmition, reception and polarization. Thus, though they are symbolically located in opposite poles, nynphs and monsters meet in the dimension of the unexpected, the unforeseen, the accidental: as Warburg nymphs hover mysteriously, floating recklessly in italian Quattrocento art pieces as paganism persistence in the Christian scenario, human imagination deformed beasts lurk in shadows ready to jump over those who crosses their paths. This encounter with nymphs or monsters is irreparable - we never escape unscathed from it.

Keywords: Monster; Nachleben; Pathosformeln.

\section{NINFAS Y MONSTRUOS: LA POST-VIDA DE FANTÁSTICAS CRIATURAS EN LA IMAGINACIÓN HUMANA}

Resumen: Este ensayo busca buscar en la oscuridad a través de la cual viajan los monstruos para comprender cómo estos seres se relacionan con las ninfas discutidas por el historiador del arte y estudioso de la imagen Aby Warburg. Ninfas y monstruos comparten características como la etéreoidad de sus cuerpos, el extrañamiento que provocan sus figuras y el desplazamiento temporal de su presencia. Para Warburg, las imágenes de ninfas en el arte renacentista son manifestaciones de pathosformeln ancestrales, legados del pasado, engramas en el sistema nervioso de los individuos. Los monstruos, a su vez, portan antiguas advertencias inscritas en sus cuerpos (Cohen, 2000). Más que eso, los vampiros, las medusas y los demonios persisten en la cultura, en el proceso de nachleben, una palabra querida por Aby Warburg - un proceso de transmisión, recepción y polarización. Así, aunque simbólicamente situadas en diferentes polos, ninfas y monstruos se encuentran en la dimensión de lo inesperado, lo imprevisto, lo accidental: mientras las ninfas de Warburg se ciernen misteriosamente, flotando imprudentemente en las obras del Quattrocento italiano como la persistencia del paganismo en la escena cristiana, las deformadas bestias de la imaginación humana acechan en las sombras dispuestas a abalanzarse sobre quienes se crucen en sus caminos. El encuentro con ninfas o monstruos es irreparable - de ahí no salimos ilesos.

Palabras Clave: Monstruos; Nachleben; Pathosformeln.

Drácula espreita nas sombras da noite. Seu corpo é etéreo, indefinido, mesclado com a escuridão que o rodeia, e seus movimentos são fluidos e leves, como se a criatura flutuasse. Não raro, ele surge de forma diferente, como nuvem de vapor, como um morcego gigante, como um grande lobo negro, como um homem elegante. Monstruoso, o vampiro primordial desafia classificações: ele está vivo e morto ao mesmo tempo; é jovem e antigo; imortal mas vulnerável. Como observa Jeffrey Jerome Cohen (2000, p. 30), o monstro é o prenúncio de uma crise de categorias. Escorregadios, esses seres escapam à classificação ordinária das coisas e se mostram como híbridos estranhos, fora da lógica e da compreensão humanas.

O vampiro, apresentado na obra de Bram Stocker, é um exemplo moderno. Antes dele, outros seres híbridos já assombravam a humanidade com suas formas horrendas e corpos deformados. O rol de monstros da mitologia grega, filhos de deuses e titãs, os gigantes e demônios bíblicos e os ghouls e djinns das narrativas árabes compõem um acervo infindável de personagens e raças que habitam a as narrativas e a imaginação humanas há milênios.

Cohen (2000, p. 26) lembra que o monstro é nascido nas encruzilhadas metafóricas como a 
encarnação do momento cultural de cada época. Como constructo e projeção, seu corpo é cultura pura e existe apenas para ser lido. Aquele que revela, aquele que mostra, aquele que alerta ${ }^{3}$. E, subitamente, ele desaparece na noite, deixando o rastro de terror de seus atos, as marcas de suas pegadas, a prova duvidosa de que ele esteve ali. Do Abominável Homem das Neves e do Monstro do Lago Ness só restam relatos confusos e fotografias borradas.

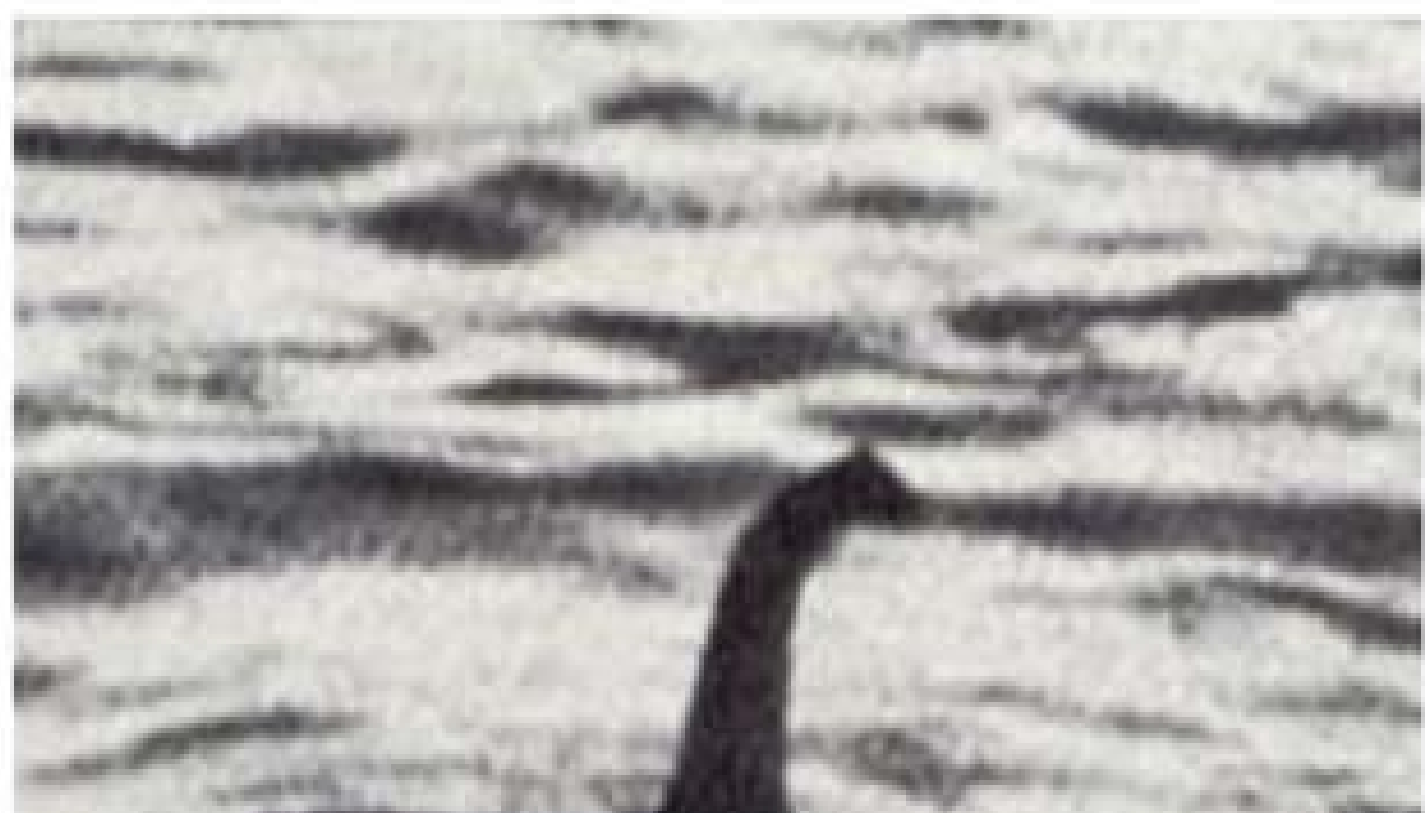

Figura 1: Fotografia do Monstro do Lago Ness e Fotograma do Pé-Grande

O monstro é, antes de tudo, uma imagem. Os nomes atribuídos a eles falham em descrever sua complexidade, seu significado, e aquilo que representam. Muitos deles sequer são nomeados, como a criatura de Frankenstein, de Mary Shelley (1997), ou o xenomorfo de Alien, de Ridley Scott (1979). São seus corpos que falam, suas formas desafiam a compreensão, atraem e repelem o olhar, pedem e convocam ao mesmo tempo em que rejeitam explicações.

O encontro com o monstro é um momento sublime - e aqui deixamos claro que nos referimos não ao termo em seu sentido usual, ordinário, mas ao que disseram Kant (2012) e Burke (1998): sublime não se confunde com o belo e guarda relações com o terrível ${ }^{4}$; sublime provoca dor e prazer e se endereça ao terrível, ao inconcebível, uma vez que ultrapassa o padrão da medida dos sentidos. Tal encontro é inesperado. O monstro nunca está do modo como imaginamos que ele está e nunca é como pensamos que ele é. O monstro é revelação, mas ao mesmo tempo uma poderosa interdição: você não deveria estar aqui.

No conto $O$ caso de Charles Dexter Ward, H. P. Lovecraft descreve o resultado de um desses encontros.

3 A etimologia da palavra "monstro" é abordada por diferentes autores, entre eles o moçambicano José Gil (2006, p. 74), que aponta que "monstrare significa muito menos 'mostrar' um objeto do que 'ensinar um determinado comportamento, prescrever a via a seguir'. O autor aponta essa dupla interpretação, do monstro como um ser que apresenta algo e, alternativamente, como aquele ser que é, em si, uma advertência divina.

4 O sublime kantiano provoca dor e prazer e se endereça ao terrível e ao que não se pode conceber, uma vez que ultrapassa o padrão da medida dos sentidos. Para Kant e Burk, o sublime estaria ligado ao trágico, à sensação de desolamento e solidão diante do grandioso que é terrível e assustador. Sobre o tema recomendamos a Crítica da Faculdade do Juizo, de I. Kant e A Philosophical Enquiry into the Origin of Our Ideas of the Sublime and Beautiful, de E. Burke. Referências completas nas referências bibliográficas deste ensaio. 
Porém, Marinus Bicknell Willet lamentou ter olhado mais uma vez; pois embora fosse um veterano da mesa de dissecação, nunca mais foi o mesmo desde então. Seria difícil explicar como uma única visão de um objeto tangível com dimensões mensuráveis poderia abalar e transformar um homem daquela forma; e podemos dizer apenas que certas entidades e silhuetas revestem-se de um poder sugestivo e simbólico que age de maneira terrível sobre a perspectiva de um pensador sensível e sussurra insinuações horrendas a respeito das relações cósmicas e realidades inomináveis por trás das ilusões protetoras de nossa visão corriqueira. (LOVECRAFT, 2014, p. 342 e 343)

O autor de contos de horror é pródigo em narrar aparições de criaturas inomináveis, que provocam efeitos de loucura e desespero em suas vítimas. Lovecraft defende que "a emoção mais antiga e mais forte do homem é o medo, e o medo mais antigo e mais forte é o medo do desconhecido" (LOVECRAFT, 2014, p. 7). Em seu conto mais conhecido, O Chamado de Cthulhu, ele apresenta o episódio no qual um grupo de marinheiros se depara com um mal ancestral.

Dos seis homens que jamais retornaram ao navio, o imediato acredita que dois tenham morrido de susto naquele mesmo instante. A Coisa era indescritível - não há idioma em que se possa expressar tais abismos de angústia e loucura imemorial, tais contradições preternaturais da matéria, da força e de toda a ordem cósmica. Uma montanha caminhava ou arrastava-se. Meu Deus! (...) A Coisa dos ídolos, o rebento verde e viscoso das estrelas havia despertado para reclamar o que era seu. (...) Passados vigesilhões de anos, o grande Cthulhu caminhava mais uma vez sobre o mundo, ávido por prazer. (LOVECRAFT, 2014, p. 91).

O corpo monstruoso fala sobre os medos, as ansiedades, as fantasias e os desejos dos indivíduos de cada época. A colcha de retalhos que é criatura de Frankenstein expõe a fragmentação da identidade do indivíduo europeu na virada do século XIX, suas dúvidas perante a ciência inovadora, seu temor da morte e da vida. O lobisomem detém a dualidade entre o homem e o animal, entre o intelecto e o instinto, mas também sobre um inimigo que está escondido entre nós (ou dentro de nós). No caso das criaturas dos contos de Lovecraft, é manifesta a fragilidade da mente humana em compreender e aceitar a natureza monstruosa desses seres. A análise desses corpos pode se prolongar, num mergulho sombrio em sua natureza reveladora.

$\mathrm{Na}$ análise da prancha 79 do Atlas Mnemosyne, Christopher D. Johnson (2013-2016), pesquisador do projeto Bilderfahrzeuge: Aby Warburg's Legacy and the Future of Iconology, desenvolvido no Warburg Institute em Londres, atenta para a presença do monstro em uma das imagens e sua dimensão corpórea. É um recorte do Hamburger Fremdenblatt, um dos mais lidos jornais diários alemães publicado na cidade de Hamburgo naquela época, de uma fotografia de um jovem nadador exibindo sua destreza física. Warburg compara a imagem do nadador ao modo como os primeiros jornais modernos divulgavam exageradamente a figura dos monstros e evidencia, em sua análise, o "hoc meum corpus est" - expressão latina que diz "este é o meu corpo" (que aparece no mistério da transubstanciação de Cristo (Mateus 20:26-28; Marcos 14:22-24; Lucas 22-19).

Em O Médico e o Monstro (2004), de Robert Louis Stevenson, o investigador pede a uma testemunha para descrever o senhor Hyde e o relato que se segue é marcado pela incerteza e pela indefinição como características do ser monstruoso.

Não é fácil de descrever. Tinha algo de falso na aparência, muito de desagradável, alguma coisa de profundamente odioso. Nunca vi homem tão antipático, nem sei bem a razão. Parecia ser vítima de alguma deformação: era a sensação que dava, ainda que não possa especificar em que parte do corpo. Uma figura extraordinária, e no entanto não sei precisar de que maneira. Não, meu amigo, de modo nenhum. É me impossível descrevê-lo. E não por falta de memória. Sou capaz de reconhecê-lo neste exato instante. (STEVENSON, 2004, p. 21 e 22)

Aqui a crise de categorias se torna evidente. A dificuldade em classificar o que aquele ser possuía de 
monstruoso é uma manifestação desse caráter indefinido, invisível e, ao mesmo tempo, perturbador. $\mathrm{O}$ incômodo e a repulsa se manifestam em todos os personagens que se encontram com o senhor Hyde, cujo nome indica sua natureza oculta.

Em Drácula (2000), o vampiro se apresenta para Jonathan Harker primeiramente como um velho estrangeiro pálido de mãos peludas. Ao longo de seu cativeiro, entretanto, o prisioneiro se depara com outras feições do monstro.

O que eu vi foi a cabeça do Conde saindo da janela. Eu não vi seu rosto, mas eu conhecia o homem pelo pescoço e pelo movimento de suas costas e braços. De qualquer forma eu não poderia deixar de reconhecer as mãos que eu tive tantas oportunidades de estudar. Eu estava no princípio interessado e de alguma forma fascinado, pois é maravilhoso como um pequeno fato interessa e fascina um homem quando ele é prisioneiro. Mas meus sentimentos mudaram para repulsa e terror quando eu vi o homem inteiro lentamente emergir da janela e começar a rastejar para baixo na parede do castelo sobre o abismo pavoroso, com seu rosto voltado para baixo com seu manto se abrindo à sua volta como grandes asas. No começo não acreditei em meus olhos. Eu pensava que fosse algum truque do luar, algum estranho efeito de sombras, mas continuei olhando e não poderia ser uma ilusão. Eu vi os dedos das mãos e dos pés rasparem as quinas das pedras, desgastadas da argamassa pelo passar de anos, e assim usando toda projeção e irregularidade para se mover para baixo com velocidade considerável, como um lagarto se move por uma parede.(STOCKER, 2000, p. 69 e 70, tradução nossa)

No romance, Drácula se apresenta com diferentes aparências. Tais visões são sempre descritas por meio de relatos de personagens, que têm vislumbres rápidos como o de Harker: obscurecidos pela noite, sob a luz do luar, através da névoa. O vampiro é visto de relance em sua forma monstruosa. Ele é fugidio.

Quando Mina Murray desperta no meio da noite com um terrível sentimento de medo e de vazio, no meio da escuridão, ela tateia à procura de Lucy e não a encontra, saindo pela cidade em busca da amiga. À lua cheia, as nuvens em movimento provocam uma alternância entre luz e sombra quando ela enxerga, por fim, uma figura branca, à distância, próxima à Igreja de Santa Maria.

O surgimento de uma nuvem foi bastante rápido para que eu pudesse ver, pois a sombra cobriu a luz quase imediatamente, mas pareceu para mim que algo escuro estava de pé por trás do banco onde a figura branca reluzia, e se curvava sobre ela. $\mathrm{O}$ que era, se homem ou fera, eu não poderia dizer. (...) Quando eu cheguei quase ao topo eu pude ver o banco e a figura branca, pois eu estava agora próxima o suficiente para distingui-la mesmo com os feitiços de sombra. Havia sem dúvida algo ali, longo e negro, curvado sobre a figura branca reclinada. Eu gritei em terror, "Lucy! Lucy!" e algo ergueu sua cabeça e de onde eu estava eu podia ver um rosto branco e olhos vermelhos brilhantes. (STOKER, 2020, p. 187 e 188 , tradução nossa)

No momento seguinte, ao contornar a igreja para alcançar a criatura, Mina encontra apenas a figura branca, sua amiga, sem sinal algum da sombra que pairava sobre ela. Toda essa cena é contada a partir dos sentidos da narradora, em especial sua visão. A imagem mental evocada pela descrição é constantemente interrompida pelas nuvens que bloqueiam o luar. Avistado, o monstro some logo que a sombra o encobre.

Assim como o senhor Hyde, Drácula também é difícil de descrever. Embora os aspectos físicos dos dois seres sejam bem diferentes, as testemunhas encontram dificuldade em categorizá-los. Hyde seria deformado, mas não se sabe dizer exatamente como. A forma sombria de Drácula não é homem nem fera, com seu corpo comprido, escuro e o rosto branco de olhos vermelhos.

Nem mesmo o fato de Victor Frankenstein ter criado o corpo monstruoso da criatura a quem conferiu a centelha da vida permite que ele escape do espanto em cada um dos desafortunados encontros com a besta.

Assim falando, percebi, na sombra, um vulto que se esgueirava detrás de um grupo de árvores perto de mim. Parei e fiquei olhando atentamente; não podia haver

R. Inter. Interdisc. Art\&Sensorium, Curitiba, v.8, n.2, p. 271 - 284 Jul.- Dez. 2021 
engano. O clarão de um relâmpago iluminou a figura e revelou perfeitamente sua forma. Sua gigantesca estatura e a deformidade de sua aparência, mais horrível do que humana, fizeram com que eu percebesse imediatamente que se tratava do desgraçado e nojento demônio ao qual eu conferira a vida. (SHELLEY, 1997, p. 88)

Em outros momentos de horror e impotência, Frankenstein tenta ferir ou capturar sua criatura, que desaparece sem deixar rastro, que é capaz de se esquivar de disparos de pistola e que o vigia de longe, como uma maldição que paira sobre o cientista.

Ao dizer isso, avistei, de repente, à distância, a figura de um homem que se encaminhava para mim com velocidade sobre-humana. Ele saltava por sobre as fendas do gelo, entre as quais eu passara com todo o cuidado e, ao se aproximar, sua estrutura parecia também exceder a de um homem. Fiquei perturbado, um véu desceu sobre meus olhos, no entanto, recuperei-me rapidamente com o vento glacial das montanhas. Percebi, à medida que a forma se aproximava (visão tremenda e odiosa!), que era o desgraçado que eu havia criado. (SHELLEY, 1997, p. 114)

Cohen (2000) defende, em suas teses, que o monstro sempre volta. No paradoxo de sua força e fragilidade, Drácula é destruído vezes sem conta nas diferentes narrativas onde surge. Seja por meio da luz solar, da decapitação ou da estaca de madeira enfiada em seu coração, há momentos em que o sanguessuga parece ser mais vulnerável que qualquer ser humano. Mas o corpo do vampiro se regenera no caixão em seu castelo, o lobisomem sempre deixa alguém ferido que se tornará uma nova fera sanguinária, a criatura de Frankenstein despertará novamente reanimada pela eletricidade. O mesmo pode ser dito dos monstros mais recentes do cinema: Freddy Krueger, de A Hora do Pesadelo (1984), Jason Vorhees, de Sexta-feira 13 (1980), e Chucky, de O Brinquedo Assassino (1988), acumulam sequências, concluídas com sua destruição e retomadas com seu retorno.

Não importa quantas vezes a sitiada Ripley, de Sigourney Weaver, destrua completamente o alienígena ambíguo que a persegue: sua monstruosa progênie retorna, pronta para perseguir outra vez, maior-do-que-nunca, no filme seguinte da série. Nenhum monstro prova a morte mais do que uma vez. A ansiedade que se condensa como vapor verde, adquirindo a forma de vampiro, pode ser temporariamente dispersada, mas o regressante - por definição - regressa. E, assim, o corpo do monstro é, ao mesmo tempo, corpóreo e incorpóreo; sua ameaça é sua propensão a mudar. (COHEN, 2000, p. 27 e 28)

Esse deslocamento não se dá somente no âmbito geográfico. Drácula apresenta um monstro do mundo antigo que deseja se atualizar. Jonathan Harker é atraído ao castelo do vampiro para formalizar o processo de aquisição de terras em Londres, onde o vilão deseja fixar sua nova morada. A luta passa a ser, então, para impedir que um demônio do passado, que habita uma terra presa às tradições, passe a espreitar na metrópole moderna. Algo semelhante se dá em Entrevista com o Vampiro (1976), de Anne Rice, no qual os sanguessugas necessitam gerar suas crias para se conectar às épocas mais recentes. A morte e ressurreição do monstro ocorrerá em virtude disso? Como um inseto que retorna ao casulo para renascer, mais forte, mais apto a sobreviver em um ambiente, local ou época diferentes?

\section{Pathos, ninfas e sintomas}

A sobrevivência dos monstros e sua persistência remete ao pós-vida das Pathosformeln, conceito trabalhado por a Aby Warburg 5 e com profundas implicações no desenvolvimento de suas ideias. As pathosformeln ou fórmula de pathos estão ligadas às forças psíquicas que estão presentes na

5 Embora se atribua muitas vezes o conceito de nachleben a Aby Warburg, o primeiro usar o termo no âmbito da História da arte foi Anton Springer, historiador da arte tcheco-germânico, que se interessava pela presença da antiguidade na Idade Média (e não no Renascimento, como é o caso do interesse de Aby Warburg). 
memória coletiva em formas espectrais e estão ligadas aos gestos, aos movimentos. São tropos visuais emocionalmente carregados que se repetem de tempos em tempos (AGAMBEN 2010; DIDI-HUBERMAN, 2013).

As pathosformeln não são meros temas ou ilustrações, mas são imagens munidas de intensa energia primitiva que evidenciam um profundo entrelaçamento entre a carga emotiva e sua fórmula iconográfica, que Felipe Charbel Teixeira aborda em seu artigo Aby Warburg e a pós-vida das Pathosformeln antigas (2010). Ali o pesquisador se debruça nos trabalhos do historiador da arte e da cultura sobre as ninfas, deusas da mitologia grega, que são representadas na arte renascentista como jovens mulheres em movimento, com traços leves, roupas e cabelos soprados pelo vento.

A primeira vez que Warburg elaborou esse neologismo foi num texto de 1905, sobre Albretch Dürer, chamado Dürer e a arte italiana, portanto doze anos após o primeiro ensaio sobre Botticelli, que viria a se tornar sua tese de doutorado. Warburg diz que no período chamado Quattrocento, especialmente na segunda metade do século $\mathrm{XV}$, os artistas italianos procuravam no arcabouço das formas da Antiguidade, tanto a calmaria clássica idealizadora (como defendiam os historiadores da arte do século XIX, contestados por Warburg) quanto o que ele chamaria de "mímica patética acentuada" - ou seja, seguindo os polos apolínio e dionisíaco discutidos por Nietzsche em $O$ nascimento da Tragédia no espírito da música.

A tese da imobilidade, da fidelidade e da "grandeza serena" - como propunha Winckelmann - foi refutada por Warburg, a partir de sua observação do efeito dos movimentos ou do vento em véus e vestidos em obras pintadas por artistas como Filippino Lippi e Sandro Botticelli. Estes não estavam preocupados, como se pensava, em retratar fielmente o mundo. As imagens que produziam traziam à tona estados anímicos turbulentos, iluminavam experiências recalcadas em zonas escuras e abissais da consciência. Eram imagens que falavam de reações fóbicas, traumáticas que estavam inscritas na cultura. Dentre essas imagens, havia um tema profundamente perturbador para Warburg: as ninfas.

Em seu L'art du portrait, em Essais florentins, Warburg (2003) diz que uma ninfa se torna "um tipo generalizado universal da mulher em movimento" (WARBURG apud TEIXEIRA 2010, p. 141), um tópico recorrente em poemas da literatura antiga - presentes em autores como Ovídio, Apuleio, Virgilio e Lucrécio - e reavivados pelos pintores florentinos dos séculos XV e XVI. Personificação da graça, da beleza e da fecundidade, habitantantes dos lagos, pradarias, florestas ou montanhas, as ninfas são divindades femininas que têm o poder de curar e nutrir.

Warburg estuda a ninfa em A primavera e em O Nascimento da Vênus, de Sandro Botticelli, e a analisa numa obra chamada $O$ nascimento de São João Batista, de Domenico Ghirlandaio. Além disso, encontramos novamente a ninfa no último, mais maduro e mais ousado projeto de Warburg:o Atlas Mnemosine, em especial nas pranchas de número 46 e 48. 


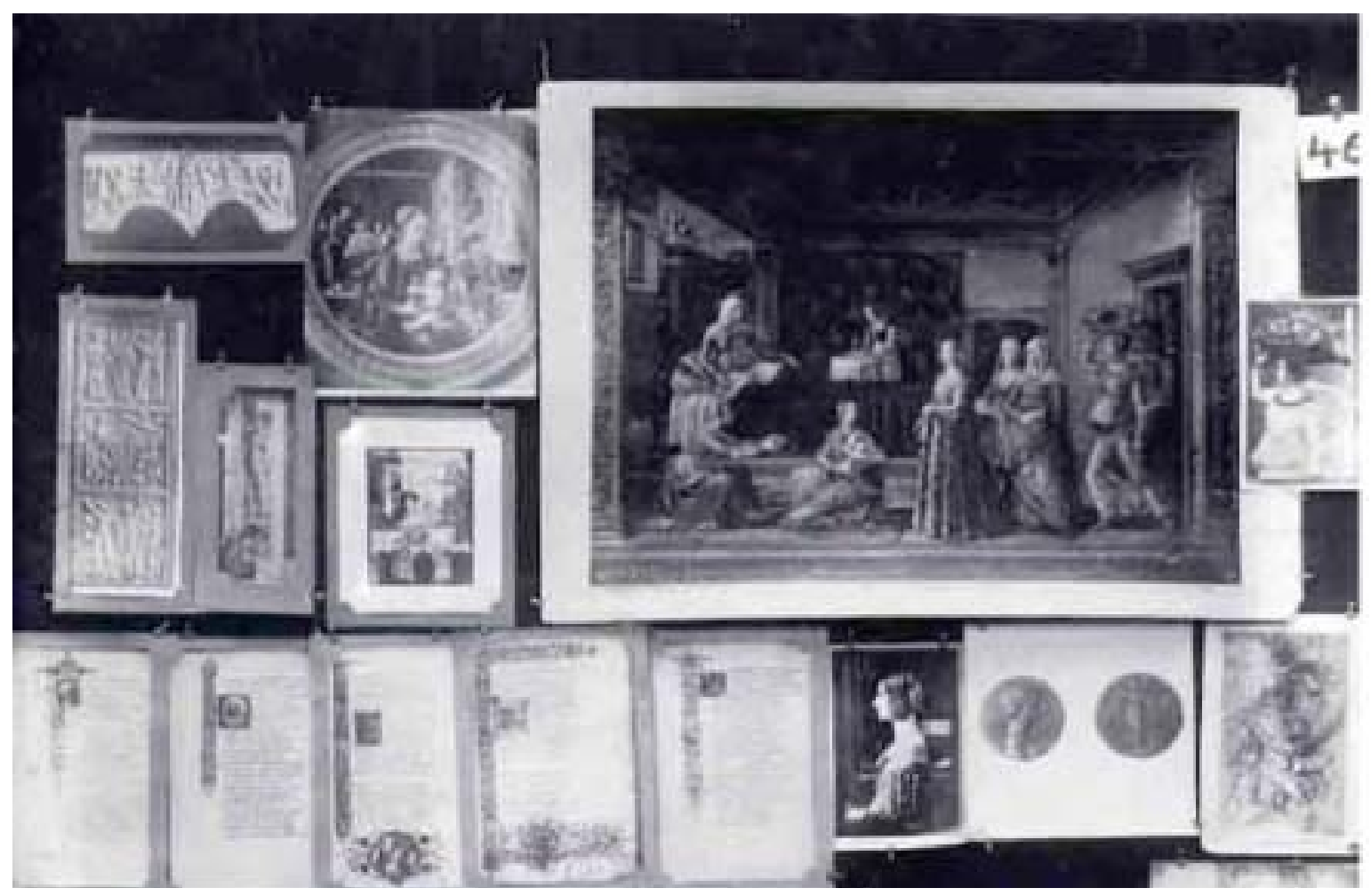

Figura 2: Atlas Mnemosyne, pranchas 46 e 48

Na tábua ou prancha 46, Warburg justapôs quase 30 fotografias, entre relevos, afrescos, pinturas e desenhos. Além de obras de Ghirlandaio, Botticelli, Rafael, nesta prancha se pode ver uma foto feita por ele mesmo de uma camponesa toscana. Warburg se pergunta qual das representações femininas do painel seria a "ninfa original", a ninfa a partir da qual todas as outras deriva. A essa pergunta responde que nenhuma delas, pois a ninfa só existe como sendo, ao mesmo tempo, original e repetição.

Em Signatura rerum, Giorgio Agamben afirma: "A ninfa, ela mesma, não é arcaica nem contemporânea, ela é diacronia e sincronia, unicidade e multiplicidade" (AGAMBEN, 2010a, p. 38). Em Ninfas, o historiador se dedica ao exame da prancha de número 46 do Atlas Mnemosine, questiona "onde está a ninfa? Qual de suas 26 epifanias é ela?" e afirma que incorreremos em erro se procurarmos "algo como um arquétipo ou um original do qual as outras derivariam. Nenhuma das imagens é original, nenhuma é simplesmente uma cópia" (AGAMBEN, 2012, p. 29). Agamben diz que a ninfa é o paradigma das imagens singulares e as imagens singulares seriam os paradigmas da ninfa. Os detalhes dos adereços, dos lenços, vestidos, mantas e dos cabelos seriam "sintomas" da ninfa. Os sintomas permanecem, mas sempre que tentamos capturá-los eles escapam - uma vez que, assim como as ninfas, os sintomas têm "pés ligeiros", "pés alados".

O conceito de sintoma é aprofundado por Didi-Huberman em Diante da imagem (2013). Para ele, um sintoma é produzido no sentido quando uma obra se apresenta de uma vez só ao olhar do espectador, liberando a meada complexa de uma memória virtual, latente e eficaz (DIDIHUBERMAN, 2013, p. 27). Os sintomas pertenceriam, para o filósofo francês, à ordem da interrupção do discurso, da legibilidade transposta, da ruptura do legível e para além dele.

Didi-Huberman aborda o sintoma a partir do viés freudiano, a exemplo dos gestos desprovidos de sentido de um corpo em crise histérica: a deformação das fisionomias, a contração despropositada de músculos e articulações, a falta de lógica de todo o movimento. Essa perda de representatividade, a incompreensão e contradição dos gestos, é, ao mesmo tempo, uma ruptura de uma significância e a instauração de uma nova estrutura significante, ainda que contraditória e dissimulada (DIDIHUBERMAN, 2013, p. 333). 
O sintoma é, portanto, uma entidade semiótica de dupla face: entre o estilhaço e a dissimulação, entre o acidente e a soberania, entre o acontecimento e a estrutura. Por isso ele se apresenta antes de tudo enquanto "signo incompreensível", como diz ainda Freud, "embora seja tão plasticamente figurado", embora sua existência virtual se imponha com tanto estilhaço, evidência ou mesmo violência. Um acidente soberano é isso. (DIDI-HUBERMAN, 2013, p. 335)

Os detalhes da ninfa seriam, nesse pensamento, desprovidos, em princípio, de significado, uma vez que rompem com a ordem estabelecida ao trazer esses elementos da antiguidade clássica para uma imagem do Renascimento. Da mesma forma, seus sintomas evocam uma memória virtual - virtus, potência - mesmo de forma acidental, dissimulada, como se fazem presentes nessas obras.

Segundo Teixeira (2010, p. 142), a presença dessas figuras míticas em Ghirlandaio e Botticelli, seria mais do que meras citações visuais de elementos da cultura antiga, mas efetivas personificações do paganismo renascentista. Warburg dizia que elas são reveladoras das pathosformeln primordiais. Ou seja, elas remetem a um conjunto de gestos, a um conjunto de posturas que estão ligadas à condições de excitação psíquica. A arte é, para ele, um mecanismo privilegiado de condensação de energias que se sintetizam em pathosformeln capazes de suscitar experiências primárias da humanidade. Assim, as pathosformeln, ao mesmo tempo em que oferecem uma forma, uma aparência, um feitio, ao movimento e às paixões, são o testemunho de estados de espírito turbulentos, de perturbações profundas.

O exame da permanência das Pathosformeln associadas às práticas primordiais de paganismo era considerado por Warburg uma etapa decisiva para a compreensão dos impulsos que, como forças inconscientes em conflito com a visão de mundo cristã, constituíram uma espécie de "fermento espiritual" da arte renascentista, condição decisiva para que ela alcançasse um historicamente reconhecido grau de excelência. (TEIXEIRA, 2010, p. 143)

Além dos trabalhos dedicados à ninfa, Aby Warburg aborda o tema em correspondências trocadas com o linguista neerlandêsentre André Jolles, linguista neerlandês. Nessas cartas, o historiador da arte responde a Jolles a respeito de uma personagem da obra $O$ nascimento de São João Batista. Na mensagem datada de 23 de dezembro de 1900, André Jolles diz o seguinte, em referência à ninfa:

Está em causa uma dama que, de forma insensível e tormentosa, se mostra coquete comigo. Iniciei um galanteio espiritual e tornei-me sua vítima (...) Mas deixe que eu te conte passo a passo, a história da minha paixão. (...) Travei conhecimento com ela numa visita semanal a uma igreja (...) Ela reside no coro de Santa Maria Novella. (JOLLES apud WARBURG, 2012, p. 2)

$\mathrm{Na}$ obra, a prima de Maria e mãe de João Batista está deitada, vestida à moda florentina, numa cama em estilo renascentista e recebe a visita de três damas da casa dos Tornabuoni. Além de Isabel e das visitas, três criadas estão presentes no quadro. Uma está de pé, servindo uma bandeja com água e suco ou refresco. As outras duas criadas estão sentadas em primeiro plano - uma com água para banhar o recém-nascido e outra que o amamenta. Então, sobre a primeira fidalga, presente próxima ao centro do quadro, diz Jolles:

De mãos poisadas sobre o ventre algo arqueado, de cabeça apoiada com magnânima singeleza no perscoço esbelto, avança ela, enquanto seu passo cauteloso a custo desloca as rígidas pregas do seu vestido de denso e compacto brocado. É de uma majestade algo superficial, não muito característica, mas de grande distinção: uma dama do mundo com inexcedível graça e de maneiras nobres mas sem muito espírito. (JOLLES apud WARBURG, 2012, p. 3)

O parágrafo seguinte diz que atrás dela estão duas figuras "velhas e apáticas", que seriam sua mãe e sua tia. André Jolles descreve, então, a oitava personagem feminina do quadro, que lhe parece a mais deslocada a enigmática: 
E por trás destas, pela porta aberta, eis que corre, não, voa, não, paira, o objecto dos meus sonhos, que, pouco a pouco, começa a adquirir as proporções de um delicioso pesadelo. Irrompe no quarto, com véu adejando, uma figura fantástica, não, uma criada, não, uma ninfa clássica, trazendo na sua cabeça um tabuleiro com magníficos frutos meridionais. (JOLLES apud WARBURG, 2012, p. 3)

Enquanto a dama que está historicamente posicionada como sendo da casa dos Tornabuoni, vestida à moda da época, ou seja, completamente inserida no contexto da obra - Jolles diz "uma dama do mundo" - é descrita como de grande distinção, "de uma majestade algo superficial", "com inexcedível graça e de maneiras nobres" mas "sem muito espírito", a outra irrompe. Ou seja, ela entra com ímpeto, inesperadamente invade a cena de modo altivo, como figura fantástica.

A resposta de Warburg à carta de Jolles, hoje guardada nos Arquivos do Instituto Warburg, não está datada. Recorremos à carta publicada no livro Ninfa Fiorentina (Warburg, 2012), que diz, por exemplo, que o afresco é uma homenagem à Virgem Maria e a João Batista, quando foi encomendado e em que condições. Discutindo a imagem da serva vestida de branco, Warburg ressalta a diferença dela para as personagens da cena e para outras obras da arte florentina do Quattrocento. No texto, ele se pergunta: “terá então, realmente essa rara e graciosa planta raízes no sombrio solo florentino?” (WARBURG, 2012, p. 6).

Podemos entender essa ninfa/serva que aparece nesse quadro de Ghirlandaio como uma metáfora da própria Renascença, uma vez que ela combina o longe e o perto, a antiguidade mítica e a intimidade doméstica, o nascimento do santo católico e o de um burguês florentino.

\section{Monstros, ninfas}

Embora monstros e ninfas pertençam a universos diferentes, sua natureza indefinida e complexa os aproxima. De caráter mítico e místico, são sintomas de um tempo, irrupções de desejos e também de medos reprimidos. Monstros e ninfas migram através dos tempos e das culturas se metamorfoseando em topos visuais distintos e transitando nas fronteiras borradas entre caos e cosmos, entre a sombra e a luz, entre o sagrado e o profano.

Até que ponto os monstros são manifestações semelhantes às ninfas de Warburg? É possível pensar a monstruosidade como um afastamento de padrões racionais - o monstro vai além do improvável, ele está na dimensão do impossível. A manifestação de seres distorcidos, deformados e híbridos é da ordem do passional, da imaginação, da criatividade desmedida. São, também, de natureza coletiva. Permanência de pathosformeln ancestrais.

Giorgio Agamben, em Aby Warburg e a ciência sem nome (2010), defende que as presenças das ninfas nas obras do Quattrocento demonstram, no pensamento de Warburg, a persistência de símbolos do paganismo no período renascentista, sobre o qual a era racional teria sido edificada. Assim, a arte da renascença seria fruto da conciliação do passado antigo com o presente cristão.

Em círculo ainda mais vasto, a aparição da "ninfa" torna-se o sinal de um profundo conflito espiritual na cultura da Renascença, que devia conciliar com audácia a descoberta dos Pathosformeln clássicos, sua carga orgíaca e o cristianismo, em equilíbrio carregado de tensões que ilustram perfeitamente personalidades, tais como o mercador florentino Francesco Sassetti, analisadas por Warburg em célebre ensaio. (AGAMBEN, 2010, p. 138)

Agamben observa ainda que o conceito de Pathosformel torna impossível separar forma e conteúdo, "pois designa o indissolúvel entrelaçamento de uma carga emotiva e de uma fórmula iconográfica" (2010, p. 132). Ele defende que, segundo Warburg, o símbolo e a imagem têm a mesma função, isto é, a do engrama no sistema nervoso do indivíduo. Warburg traz o conceito de engrama de Semon, como sendo a cristalização da carga energética e experiência emotiva, herdadas pela memória social e efetivadas ao contato da "vontade seletiva" de determinada época (TEIXEIRA, 2010, p. 143). 
É por isso que Warburg fala frequentemente dos símbolos como "dinamogramas" transmitidos aos artistas no estado de tensão máxima, mas não polarizados quanto a sua carga energética - ativa ou passiva, negativa ou positiva -, sua polarização, quando se encontram uma nova época e de suas necessidades vitais, pode causar a inversão completa de sua significação. (AGAMBEN, 2010, p. 136)

Como as ninfas de Warburg, os vampiros, os fantasmas e outros monstros podem ser percebidos como imagens carregadas de potência, capazes de eclodir a qualquer momento, como um ovo de alienígena vagando pelo espaço sideral, pronto para ser colhido por uma tripulação exploradora. Deste modo, esses seres retornam revestidos de sentido e, ao mesmo tempo, preparados para tecer novos alertas. O pós-vida do monstro é mais que seu renascimento ou sua sobrevivência, mas sua persistência, sua nachleben der antike.

Agamben destaca que Warburg foca sua atenção no problema dos símbolos e de sua existência na memória social, uma vez que a cultura é sempre um processo de nachleben, isto é, de transmissão, recepção e polarização.

Mesmo o tema da "vida póstuma" da civilização pagã, que define uma das principais linhas de força da reflexão de Warburg, não se compreende a não ser que o recoloquemos nesse horizonte mais vasto: aí, as soluções estilísticas e formais adotadas a cada vez pelos artistas se apresentam como decisões éticas definindo a posição dos indivíduos e de uma época em relação à herança do passado, e a interpretação do problema histórico se torna, por isso mesmo, um "diagnóstico" do homem ocidental lutando para se curar de suas contradições e para encontrar, entre o antigo e o novo, sua própria moradia vital. (AGAMBEN, 2010, p. 135)

Em outras palavras, a presença das ninfas nos quadros de Ghirlandaio e Botticelli são reveladores das formas que esses artistas e a sociedade nas quais estavam inseridos lidavam com o passado pagão, sinalizando uma busca de conciliação entre valores contraditórios. De forma similar, a presença de seres monstruosos propõe a possibilidade de análise da condição humana em cada época.

A pesquisadora Zakiya Hanafi se debruça, em seu livro The monster in the machine (2000), sobre o fenômeno da monstruosidade e sua relação com o homem e a ciência. Para ela, o monstro é um conceito necessário para definir aquilo que não somos. Isto é, o ser monstruoso é aquilo que está na fronteira exterior do ser humano e, portanto, o monstro é definidor do homem.

O monstro sagrado se torna extinto no mundo ocidental, mas a monstruosidade - a ameaça pervasiva à humanidade que habita os limites de nosso passado animal e nosso futuro mecânico - nunca vai morrer. Uma das coisas que torna difícil rastrear o monstro é que ele está constantemente mudando seus atributos. Isso se dá porque nós humanos estamos constantemente mudando nossos atributos também. (HANAFI, 2000, p. 218, tradução nossa)

Hanafi observa que os monstros da atualidade mantém, mais do que nunca, conexões espetaculares com o mecânico, reflexo das relações que o homem vem desenvolvendo com dispositivos eletrônicos, da extensão das mentes na Internet e da visão de nossa imaginação como algum tipo de realidade virtual. Para ela, nossa auto-imagem modelada em metáforas digitais também leva nossos monstros para o cenário cibernético, como híbridos de homens e máquinas e, nosso favorito, o extraterrestre, portador de tecnologia superior. "Talvez a verdade seja que todos nós almejamos secretamente ser alienígenas" (HANAFI, 2000, p. 2018, tradução nossa).

O filósofo moçambicano José Gil, em seu livro Monstros (2006), reforça o pensamento de Hanafi sobre o monstro como definidor do homem. Para ele, os monstros existem para mostrar o que não somos e o que poderíamos ser: "Entre estes dois pólos, entre uma possibilidade negativa e um acaso possível, tentamos situar a nossa humanidade de homens" (GIL, 2006, p. 12). Dessa forma, o monstro seria o não-humano, uma negação que nos afirma. 
O monstro é pensado como uma aberração da "realidade" (a monstruosidade é um excesso de realidade) a fim de induzir, por oposição, a crença na "necessidade da existência" da normalidade humana. Uma existência que seja um dado adquirido: é imprescindível não questionar a nossa identidade de homens como seres reais. A nossa facticidade é de direito. (GIL, 2006, p. 18)

No que diz respeito ao trânsito dos monstros entre diferentes épocas, Jeffrey Jerome Cohen avalia essa transculturalidade e transtemporalidade na figura do vampiro imortal, cuja presença é identificada no Egito antigo e na moderna Hollywood. Para ele, cada reaparição e sua respectiva análise requerem um duplo ato de construção e reconstrução (COHEN, 2000, p. 29).

Cohen reconhece que a presença do monstro antigo em uma época diferente vai além de sua nova roupagem. Enquanto no filme expressionista alemão Nosferatu, de 1922, a praga e a degradação corporal se manifestam como elementos subterrâneos do desejo que sobe à superfície, nos mais recentes Drácula de Bram Stoker (1992) e Entrevista com o Vampiro (1994) a homossexualidade surge tanto nas figuras das lâmias (as noivas de Drácula que seduziam Jonathan Harker) quanto na figura sexualmente ambígua do vampiro Lestat (COHEN, 2000, p. 29). Para ele, os monstros devem ser analisados no interior da complexa teia de relações sociais, culturais, literárias e históricas na qual se manifestam.

Uma "teoria dos monstros" deve, portanto, preocupar-se com séries de momentos culturais, ligadas por uma lógica que ameaça, sempre, mudar; fortalecida pela mudança e pela fuga, pela impossibilidade de obter aquilo que Susan Stewart chama de a desejada "queda ou morte, a paralisação" de seu gigantesco sujeito, a interpretação monstruosa é tanto um processo quanto uma epifania, um trabalho que deve se contentar com fragmentos (pegadas, ossos, talismãs, dentes, sombras, relances obscurecidos - significantes de passagens monstruosas que estão no lugar do corpo monstruoso em si). (COHEN, 2000, p. 29 e 30)

\section{Considerações Finais}

A presente reflexão aponta para possíveis elos no que dizem respeito ao que Cohen chamou de transtemporalidade e da persistência das criaturas monstruosas vivas na cultura. As relações dessas características com os conceitos de Pathosformeln e Nachbelen der Antike de Aby Warburg se evidenciam, também, ao tratarem das figuras míticas das ninfas e de outros seres fantásticos. São muitas as características em comum: a eterealidade das formas, o deslocamento temporal, a potência, a paixão, a turbulência e a perturbação que evocam. Mesmo a ideia de encontro acidental, o aspecto efêmero desses acontecimentos e a difusão de suas formas na visão das testemunhas são aspectos sobre os quais é oportuno se debruçar.

Com efeito, os seres monstruosos e as ninfas irrompem em suas aparições fugidias, habitando espaços discretos, mas ainda assim se fazendo visíveis. José Gil observa que os monstros estão presentes em catedrais não nos altares, retábulos ou colunas, mas nos cantos das gárgulas, na borda das cornijas, nas cantoneiras entre as figuras de santos, "fundindo-se em interstícios, espiando das frestas, dissimulando-se na sombra para melhor nos surpreender" (GIL, 2006, p. 58).

Nos manuscritos, o seu lugar é igualmente característico: estendem-se pelas margens dos Bestiários, dos Livros de Salmos, Livros de Horas, dos Romances. Decoram as maiúsculas que iniciam os parágrafos e ocupam os espaços em branco que terminam as linhas. Lugares-limite também, lugares marginais que rodeiam o texto, quer dizer, a ordem, o sagrado, o "simbólico". A inventividade, o extraordinário movimento das figuras fantásticas opõem-se à imobilidade rígida das letras que compõem a orto-grafia. (GIL, 2006, p. 58)

Os monstros e as ninfas são exemplos de uma categoria maior de entidades fantásticas que invadem nosso mundo, que visitam o homem ao longo dos séculos. Essa ideia pode levar a crer que suas aparições cumpririam um propósito - uma advertência, uma lembrança, um augúrio - mas pode ser 
presunçoso pensar que sejamos capazes de compreender as intenções desses seres ou mesmo que essas intenções existam. As entidades ancestrais de Lovecraft, por exemplo, não possuem interesse algum nos assuntos humanos e toda a ciência desenvolvida pela humanidade é incapaz de delinear qualquer sentido para suas existências. Para o escritor, a ignorância humana não é apenas um fato constatado, mas também uma característica desejada e necessária para a manutenção da sanidade mental, como se vê no parágrafo inicial de O Chamado de Cthulhu:

A coisa mais misericordiosa do mundo é, segundo penso, a incapacidade da mente humana em correlacionar tudo o que sabe. Vivemos em uma plácida ilha de ignorância em meio a mares negros de infinitude, e não fomos feitos para ir longe. As ciências, cada uma empenhando-se em seus próprios desígnios, até agora nos prejudicaram pouco; mas um dia a compreensão ampla de todo esse conhecimento dissociado revelará terríveis panoramas de realidade e do pavoroso lugar que nela ocupamos, de modo que ou enlouqueceremos com a revelação ou então fugiremos dessa luz fatal em direção à paz e ao sossego de uma nova idade das trevas (LOVECRAFT, 2014, p. 64).

Tendo escrito o conto há quase cem anos, em 1926, é difícil imaginar se Lovecraft consideraria os avanços científicos do último século como significativos ou, ainda, pouco prejudiciais. Entretanto, continuamos a tarefa de ampliar a compreensão desse conhecimento dissociado, atentos a revelações enlouquecedoras e evitando o início de uma nova idade de trevas. O trabalho de investigação deve persistir, portanto, seguindo pegadas úmidas na escuridão, em busca de um breve luar que possa permitir o vislumbre rápido e revelador do corpo monstruoso ou de uma donzela de pés ligeiros.

\section{REFERÊNCIAS BIBLIOGRÁFICAS}

AGAMBEN, G. Aby Warburg e a ciência sem nome. In: BARHOLOMEU, C. (org.). Dossiê Aby Warburg. Revista Arte e Ensaios. Rio de Janeiro, n. 19, p. 132-143, jan. 2010.

AGAMBEN, G. Signatura rerum: sobre el método. Barcelona: Anagrama, 2010a.

AGAMBEN, Giorgio. Ninfas. São Paulo, Hedra, 2012.

BURKE, E. A Philosophical Enquiry into the Origin of Our Ideas of the Sublime and Beautiful. Oxford, Oxford UK, 1998.

COHEN, J. J. A cultura dos monstros: sete teses. In: SILVA, T. (org.). Pedagogia dos monstros: os prazeres e os perigos da confusão de fronteiras. Belo Horizonte: Autêntica, 2000.

DIDI-HUBERMAN, G. Diante da imagem: questão colocada aos fins de uma história da arte. São Paulo: Editora 34, 2013.

HANAFI, Z. The Monster in the Machine: Magic, Medicine and the Marvelous in the Time of the Scientific Revolution. Durham: Duke University Press, 2000.

JOHNSON, C. D. Mnemosyne - meanderings through Aby Warburg's Atlas: a biographical fragment. A Biographical Fragment. 2013-2016. Disponível em: <https://warburg.library. cornell.edu/about/aby-warburg>. Acesso em: 01 jan. 2021.

JOHNSON, C. D. Ten panels from the Mnemosyne Atlas: browse themes sequence 3 (2 of 2). Browse themes sequence 3 (2 of 2). 2013-2016. Disponível em: $<$ https://warburg.library.cornell.edu/image-group/panel-79-sequence-3-2-2>. Acesso em: 01 jan. 2021.

KANT, I. Crítica da Faculdade do Juízo. São Paulo, Forense Universitária, 2012. 
LOVECRAFT, H. P. O caso de Charles Dexter Ward. In: DOLHNIKOFF, Luis (org.). Os melhores contos de H. P. Lovecraft. São Paulo: Editora Hedra, 2014.

SHELLEY, M. Frankenstein. Traduc?a?o: Me?cio Araujo Jorge Honkins. Porto Alegre: L\&PM, 1997.

STEVENSON, R. L. O Médico e o Monstro. São Paulo: Martin Claret, 2000.

STOKER, B. Dracula. Cupertino: Apple Books Classic, 2020. E-Book. Acesso em 16 out 2020.

TEIXEIRA, F. C. Aby Warburg e a pós-vida das Pathosformeln antigas. História da Historiografia: International Journal of Theory and History of Historiography, v. 3, n. 5, p. 134-147, 13 de setembro de 2010.

WARBURG, A. Dürer e a arte italiana. In: WAIZBORT, Leopoldo (org.). História de fantasma para gente grande: escritos, esboços e conferências. Tradução de Lenin Bicudo Bárbara. São Paulo: Companhia das Letras, 2015.

WARBURG, A. L'art du portrait. Essais Florentins. Paris: Klincksieck, 2003.

WARBURG, A. A ninfa: uma troca de correspondências entre André Jolles e Aby Warburg. $A$ presença do antigo - escritos inéditos - volume 1. Campinas, editora da Uncamp, 2018 [essas correspondências também podem ser acessadas no projeto

WARBURG, A. Ninfa Fiorentina: Fragmentos de um projecto sobre Ninfas, trad. A. Morão, Lisboa: KKYM, 2012. Disponível em <https://proymago.pt/Warburg-Txt-3>. Acesso em 29 mai 2020]. 